\title{
ERRATUM
}

\section{Hypertonic saline reduces cumulative and daily intracranial pressure burdens after severe traumatic brain injury}

TO THE EDITOR: After publication of our article, "Hypertonic saline reduces cumulative and daily intracranial pressure burdens after severe traumatic brain injury" (J Neurosurg 122:202-210, 2015), we discovered errors in Table 4. These errors occurred after data analysis and during preparation of the table. They do not impact the content or results of the publication in any way.

In the original version of Table 4, the values given for the characteristics "Abnormal pupils (no. [\%])," "Hypotension (no. [\%])," and "Craniotomy (no. [\%])" were listed as 6 (17.1), 8 (23.5), and 7 (20.6), respectively. These values should have been 4 (16.0), 4 (16.0), and 6 (24.0), respectively.

We apologize for the error and appreciate the opportunity to set the record straight by publishing this erratum. The figure has been corrected online as of October 30, 2015, and appears below.

Halinder S. Mangat, M.D.

Weill Cornell Medical College, New York, NY

\section{INCLUDE WHEN CITING}

Published online October 30, 2015; DOI: 10.3171/2015.10.JNS132545a.

(c)AANS, 2016

TABLE 4. Baseline characteristics of the 2 study groups after matching

\begin{tabular}{|c|c|c|c|c|}
\hline Characteristic & HTS & Mannitol & $\begin{array}{c}\text { Standardized } \\
\text { Difference (\%) }\end{array}$ & p Value* \\
\hline No. of patients & 25 & 25 & & \\
\hline Age in yrs (mean \pm SD) & $34.96 \pm 15.41$ & $36.68 \pm 16.90$ & 10.1 & 0.96 \\
\hline GCS score (mean \pm SD) & \multicolumn{2}{|c|}{$5.40 \pm 1.55$} & & \\
\hline Abnormal pupils (no. [\%]) & \multicolumn{2}{|c|}{$4(16.0)$} & & \\
\hline Hypotension (no. [\%]) & \multicolumn{2}{|c|}{$4(16.0)$} & & \\
\hline Craniotomy (no. [\%]) & \multicolumn{2}{|c|}{$6(24.0)$} & & \\
\hline Day of ICP monitor insertion (mean \pm SD) & \multicolumn{2}{|c|}{$1.16 \pm 0.47$} & & \\
\hline CT scan abnormalities (no. [\%]) & $23(92.0)$ & $24(96.0)$ & 16.9 & 0.56 \\
\hline
\end{tabular}

\footnotetext{
* The $p$ values were calculated using the Wilcoxon signed-rank or $\mathrm{CMH}$ test for paired data.
} 